\title{
GESTÃO DOCUMENTAL DE UMA UNIVERSIDADE PÚBLICA NO OESTE DO ESTADO DO PARANÁ
}

\section{DOCUMENT MANAGEMENT OF A PUBLIC UNIVERSITY IN THE WEST OF THE STATE OF PARANÁ}

Tatianne Akaichia

Franciele Merlob

\begin{abstract}
RESUMO
Introdução: O trabalho relata a experiência das atividades arquivísticas desenvolvidas em uma universidade pública do oeste do Paraná. Objetivo: Objetivo foi apresentar as principais ações executadas no âmbito da instituição até o presente momento. Metodologia: De 2011 até o segundo semestre de 2016 foram criadas comissões; ministrado um curso, realizadas visitas técnicas, construída uma página na web, entre outras ações. Resultados: Como resultado, observou-se que as práticas adotadas mostram ser satisfatórias no que diz respeito ao desempenho das atividades acadêmicas e administrativas. Conclusões: Concluiu-se que existe interesse, consideração e respeito pelos servidores da universidade acerca do tratamento, da organização e da preservação do patrimônio documental da instituição.
\end{abstract}

Descritores: Arquivo institucional. Gestão documental. Organização de documentos.

\section{INTRODUÇÃO}

Diariamente é produzido um grande volume de documentos por todas as instituições, tanto públicas como privadas e, dessa forma, observa-se que a organização dessa documentação tem sido um dos grandes desafios da arquivística contemporânea. Segundo Sousa (2008), compreender o modo

a Doutoranda do Programa de Pós-Graduação em Ciência da Informação (PPGCl) da Universidade Estadual Paulista (UNESP). E-mail: tatianne.akaichi@gmail.com

b Mestre em Patrimônio Cultural pela Universidade Federal de Santa Maria (UFSM). E-mail: francielemerlo@gmail.com 
como as instituições estruturam e executam suas funções e atividades é entender como os documentos são acumulados, uma vez que a medida em que os documentos vão sendo acumulados, estabelecem relações entre si, ou seja, devem seguir o princípio de respeito aos fundos, em que os documentos são vinculados uns aos outros no momento em que são produzidos e recebidos, provenientes de uma instituição ou pessoa, e não devem ser misturados aos de outras entidades produtoras.

Em relação a tal aspecto, nas universidades as atividades que atendem a finalidade do órgão envolvem o ensino, a pesquisa e a extensão, ou seja, estas são as atividades-fim da instituição. Porém, de igual importância, são as atividades-meio que dão condições para que a entidade atinja seu propósito principal. Assim sendo, cotidianamente, é produzida, por todos esses setores, uma significativa quantidade de documentos que necessita ser classificada, organizada, tratada, avaliada e descrita, objetivando possibilitar o acesso às informações.

O Conselho Nacional de Arquivo (CONARQ), vinculado ao Arquivo Nacional do Ministério da Justiça, responsável por definir a política nacional de arquivos públicos e privados e exercer orientação normativa visando à gestão documental, em sua primeira Resolução de 1995, dispõe sobre a necessidade da adoção de planos e ou códigos de classificação de documentos nos arquivos correntes, que considerem a natureza dos assuntos resultantes de suas funções e atividades.

Nesse contexto, após passar por várias revisões, em 2001, foi aprovado, por meio da Resolução $n^{\circ} 14$ do CONARQ, o código de classificação de documentos de arquivo e a tabela de temporalidade relativos às atividadesmeio, para serem aplicados e adotados na Administração Pública. Em 2011, foi aprovado por meio da Portaria $\mathrm{n}^{\circ} 092^{1}$ do Arquivo Nacional, o código de classificação, a tabela de temporalidade e destinação de documentos de arquivo referentes às atividades-fim das Instituições Federais de Ensino Superior (IFES). Desse modo, no caso especificamente das IFES, esses dois

1 Portaria AN/MJ no 092, aprovada em 23 de setembro de 2011. Disponível em: $<$ http://pesquisa.in.gov.br/imprensa/jsp/visualiza/index.jsp?jornal=1\&pagina=26\&data=26/09/20 11>. Acesso em: 07 ago. 2016. 
planos de classificação e tabelas de temporalidade constituem elementos essenciais à organização dos arquivos, permitindo o acesso aos documentos por meio da racionalização e controle eficaz das informações contidas nesses registros.

É importante ressaltar que o método de classificação utilizado é por assunto, com a finalidade de agrupar os documentos sob um mesmo tema e conteúdo, como forma de agilizar a recuperação da informação e facilitar a prática arquivística relacionada à avaliação, seleção, eliminação, transferência, recolhimento, preservação e ao acesso à documentação. Nesses planos de classificação de documentos das atividades administrativas e acadêmicas, a sistematização utilizada é a decimal ${ }^{2}$ e os assuntos partem sempre do geral para o particular e recebem códigos numéricos, sob os quais refletem a hierarquia funcional do órgão, definida por meio de classes, subclasses, grupos e subgrupos. O sistema decimal de classificação por assunto refere-se ao código numérico dividido em dez classes e estas, por sua vez, em dez subclasses e assim sucessivamente (ARQUIVO NACIONAL, 2001).

Atualmente, os códigos de classificação dos documentos das atividadesmeio são constituídos de apenas duas classes, são elas: a classe 000 Administração Geral e a classe 900 - Assuntos Diversos. No que concerne aos códigos de classificação das atividades-fim há cinco classes criadas: classe 100 - Ensino Superior; 200 - Pesquisa; 300 - Extensão; 400 - Educação Básica e Profissional; 500 - Assistência Estudantil e três classes vagas para possíveis expansões $\mathrm{e}$ inserções de documentos referentes às novas atividades desenvolvidas pelas universidades e institutos federais, que, ao serem propostas, deverão ser submetidas à aprovação pelo Arquivo Nacional (CONSELHO..., 2016).

Lopes $(2000$, p. 267) chama atenção para o fato que "[...] acervos guardados sem qualquer classificação estão no limbo do universo do conhecimento, porque não é possível acessar esse conteúdo informacional

2 A Classificação Decimal de Dewey (CDD), idealizado pelo bibliotecário americano Melvil Dewey, em 1873, foi criada para classificar e organizar livros. Esse sistema divide 0 conhecimento humano em dez grandes classes, cada uma dessas classes em dez subclasses, cada subclasse em outras dez subclasses (SCHELLENBERG, 1974). 
existente". É significativo frisar que a classificação é uma das atividades do processo de gestão de documentos arquivísticos, a qual inclui procedimentos e técnicas específicas que permitem maior eficiência e agilidade no gerenciamento, controle, recuperação e disseminação das informações das instituições. Para Albuquerque (2012, p. 103):

\begin{abstract}
Classificar é realizar uma série de atividades que dividem ou juntam elementos diferentes e semelhantes, com intuito de conhecer, entender e dispor esses elementos de forma que possam ser encontrados, mas também compreendidos dentro de um período ou esquema.
\end{abstract}

Do mesmo modo, a avaliação documental é uma relevante etapa do processo de gestão de documentos de arquivo, a qual consiste em analisar e estabelecer prazos de guarda e destinação aos documentos (custódia permanente ou eliminação), de acordo com os valores primário ou secundário que Ihe são atribuídos. $O$ valor primário diz respeito ao fim pelo qual 0 documento foi produzido (administrativo, legal e fiscal), e o valor secundário refere-se aos documentos com importância probatória e testemunho histórico (SCHELLENBERG, 1974). A metodologia de avaliação documental é realizada com base na tabela de temporalidade que registra o ciclo de vida dos documentos (fase corrente, intermediária e permanente) e contém os períodos de arquivamento da documentação que devem ser seguidos (BERNARDES, 1998).

Em síntese, pode-se dizer que a utilização dos instrumentos de classificação e da tabela de temporalidade, ou seja, as atividades de gestão documental, além de possibilitarem o controle e a rápida recuperação de informações, e contribuírem na racionalização da produção e fluxos documentais, na correta avaliação e destinação dos documentos produzidos e recebidos, aumentam a eficácia dos serviços arquivísticos prestados na instituição.

\title{
2 ARQUIVO
}

Duas definições relativas aos arquivos merecem atenção. $O$ primeiro conceito envolve o arquivo como um conjunto de documentos (produzidos e

Inf. Inf., Londrina, v. 23, n. 2, p. $619-632$, maio/ago. 2018 http://www.uel.br/revistas/informacao/ 
recebidos) que, independentemente da natureza do documento ou do suporte da informação, são reunidos por acumulação ao longo das atividades de pessoas físicas ou jurídicas, públicas ou privadas. O segundo entendimento é o arquivo como uma entidade ou órgão administrativo responsável pela custódia, pelo tratamento documental e pelo acesso às informações (ARQUIVO NACIONAL, 2005). Em suma, os arquivos têm por finalidade disponibilizar a documentação acumulada, e atender seus usuários de forma que possibilite a recuperação da informação. Seu papel social está vinculado à guarda da documentação histórica e cultural de uma determinada instituição e sociedade.

Segundo a natureza da entidade produtora, os arquivos podem ser caracterizados como arquivo público, que se referem ao conjunto de documentos de um órgão público (federal, estadual ou municipal) produzidos no exercício de suas funções, ou como arquivo privado, que corresponde ao conjunto de documentos de uma entidade de direito privado, família ou pessoa em decorrência de suas atividades (BRASIL, 1991).

De acordo com Thomassen (2006, p. 7), os arquivos "[...] funcionam como memória dos produtores de documentos e da sociedade de forma geral. Tanto os produtores de documentos públicos quanto os de privados mantêm registros para lembrar ou para serem lembrados." Em linhas gerais, a importância que o arquivo representa para a sociedade envolve os seguintes aspectos: atender à administração, subsidiando com informações para as tomadas de decisões; à sociedade, proporcionando o acesso à informação pública, tornando transparentes as ações que estão sendo desenvolvidas pelo Estado, e, do mesmo modo, possibilitando aos cidadãos a visibilidade de onde os recursos financeiros estão sendo empregados. Em suma, por meio das informações contidas nas documentações é possível informar, comprovar fatos e atos, preservar a memória da instituição e servir como fonte de pesquisa histórica e científica.

Nesse sentido, convém expor que 0 arquivo não funciona como um espaço ou um depósito que somente armazena e acondiciona a documentação sem critério, lógica ou sistematização. Em outras palavras, conforme expõe Bacellar (2005), para que ele não seja considerado como um "arquivo morto", 
ignorando a preciosidade de muitos documentos ali esquecidos, é essencial que se adotem medidas e técnicas apropriadas de gestão documental, visando atender sua principal finalidade de dar acesso às informações que contêm dentro do acervo, de maneira facilitada, ágil e resguardando as informações classificadas como sigilosas e pessoais, quando necessário.

\section{GESTÃO DE DOCUMENTOS}

De acordo com a Lei $n^{\circ} 8.159$, de 08 de janeiro de 1991, artigo $3^{\circ}$, a gestão de documentos é "o conjunto de procedimentos e operações técnicas referentes à sua produção, tramitação, uso, avaliação e arquivamento em fase corrente e intermediária, visando a sua eliminação ou recolhimento para guarda permanente" (BRASIL, 1991).

Dentre os diversos benefícios da gestão de documentos de arquivo, pode-se destacar: o controle sistemático da documentação produzida, recebida e acumulada; a agilidade e a facilidade na recuperação das informações; a contribuição para a tomada de decisão; a transparência das ações; a correta destinação dos documentos; a redução da massa documental, consequentemente, a otimização de espaços físicos, economia de recursos humanos, materiais e financeiros e gastos desnecessários e a preservação do patrimônio documental (ROUSSEAU; COUTURE, 1998; MORENO, 2008).

A gestão documental possui três tipos de fases: a produção, a utilização e a destinação. A primeira trata da otimização da produção de documentos em razão de atividades específicas do órgão, evitando a produção daqueles não essenciais e diminuindo o fluxo documental a ser gerenciado nas demais fases. Já a utilização diz respeito ao controle do fluxo percorrido pelos documentos, necessário ao cumprimento de sua função administrativa, assim como sua guarda após cessar o trâmite. No que concerne à destinação, ela envolve as atividades de análise, seleção e fixação de prazos de guarda dos documentos, ou seja, implica decidir e definir quais documentos serão eliminados ou preservados permanentemente (JARDIM, 1987).

Inicialmente, para se implementar a gestão de documentos é necessária 
a criação de um plano de classificação. Um plano de classificação de documentos é o esquema de distribuição de documentos em classes e subclasses, seguindo uma estrutura hierárquica e lógica que reflete as funções e atividades de uma instituição produtora de documentos (ARQUIVO NACIONAL, 2005). As principais etapas da elaboração do plano de classificação compreendem os seguintes levantamentos: identificação das funções e atividades desenvolvidas na instituição; estudo da legislação e documentos internos de normatização; entrevistas com especialistas de cada área do órgão; identificação das tipologias, dos fluxos documentais e finalidades dos documentos. No entanto, como mencionado, o Arquivo Nacional elaborou um plano de classificação para os órgãos da Administração Pública.

Para Camargo e Bellotto (1996, p. 16), a classificação documental refere-se às "[...] operações que, de acordo com as diferentes estruturas, funções e atividades da entidade produtora, visam distribuir os documentos de um arquivo." Nesse sentido a classificação consiste na análise e identificação do conteúdo de documentos recebidos e produzidos na instituição; a seleção da categoria de assunto sob a qual os documentos sejam recuperados e, por fim, na atribuição de códigos. Em síntese, a sua importância é dar visibilidade às funções e as atividades do organismo produtor de arquivo, deixando claras as ligações entre os documentos, ou seja, na classificação dos documentos devem ser seguidos os princípios arquivísticos: o princípio da proveniência ${ }^{3}$ e 0 princípio do respeito à ordem original 4 .

Outro procedimento da gestão de documentos de arquivo é a avaliação. De acordo com Bernardes (1998), versa em identificar valores e definir prazos de guarda para os documentos independentemente de seu suporte. Oliveira (2012) salienta que o processo de avaliação dos documentos deve ser feito de maneira criteriosa, no qual não se pode preservar tudo e não se pode eliminar tudo. Para a autora, não se pode eliminar os documentos utilizando como base

3 Princípio básico da arquivologia segundo o qual o arquivo produzido por uma entidade coletiva, pessoa ou família não deve ser misturado aos de outras entidades produtoras (ARQUIVO NACIONAL, 2005).

${ }_{4}$ Princípio segundo o qual os documentos devem ser preservados na ordem que thes atribuíram seus criadores (SCHELLENBERG, 1974). 
a necessidade de se obter espaço, mas sim os critérios norteadores de avaliação e seleção dos documentos devem ser conduzidos por aqueles que resultarão na memória institucional.

Quanto às atividades de descrição incluem a análise e a representação da informação documental, bem como a elaboração de instrumentos de consultas e pesquisas: guias, catálogos, inventários e índice, de modo que o conteúdo e a localização dos documentos se tornem conhecidos e disponíveis. Em suma, a principal finalidade dessas atividades de classificação, avaliação e descrição, é tornar os documentos acessíveis ao uso, por essa razão é essencial definir os métodos e diretrizes a seguir, e em geral, desenvolver uma organização eficaz (SCHELLENBERG, 1974).

Assim, é necessário que a documentação passe por um tratamento arquivístico da atividade administrativa, no arquivo corrente e intermediário até o processo de avaliação para a guarda permanente ou eliminação, para que a informação registrada, de caráter informativo, probatório, testemunho ou histórico, possa ser disponibilizada ao usuário com o intuito de produzir conhecimento por meio do desenvolvimento de pesquisa, reflexões e estudos científicos ou, ainda, para outras finalidades.

\section{ATIVIDADES ARQUIVÍSTICAS DESENVOLVIDAS NO ÂMBITO DA UNIVERSIDADE}

A Universidade Federal da Integração Latino-Americana (UNILA), criada pela Lei oㅡ 12.189, de 12 de janeiro de 2010, localizada em Foz do Iguaçu, Estado do Paraná, tem característica bilíngue (português e espanhol), tendo em vista que, aproximadamente, metade das vagas dos cursos é destinada aos alunos estrangeiros advindos de diversos países, como: Argentina, Paraguai, Uruguai, Peru, Chile, Bolívia, entre outros, assim como o quadro docente é formado por professores brasileiros e provenientes de diferentes nacionalidades. A Lei no 12.189/2010, no seu Artigo 2º, dispõe que: 
A Unila terá como objetivo ministrar ensino superior, desenvolver pesquisa nas diversas áreas de conhecimento e promover a extensão universitária, tendo como missão institucional específica formar recursos humanos aptos a contribuir com a integração latino-americana, com 0 desenvolvimento regional e com o intercâmbio cultural, científico e educacional da América Latina, especialmente no Mercado Comum do Sul - MERCOSUL.

Atualmente, a UNILA oferece 29 cursos de graduação, em diversas áreas do conhecimento, seis cursos de especialização e cinco mestrados. Vale dizer que, no momento presente, contêm matriculados na graduação 3.150 alunos, existem vigentes 260 projetos de pesquisas, coordenados pelos professores da universidade e 140 ações de extensão em execução. O quantitativo de servidores é composto por 332 docentes e 512 técnicos ${ }^{5}$ trabalhando em distintas unidades administrativas, entre eles, os arquivistas lotados na Seção de Protocolo e Arquivo, vinculados à Pró-Reitora de Administração, Gestão e Infraestrutura (PROAGI).

Adentrando as informações acerca do setor responsável pela gestão, guarda e preservação documental, a Seção de Protocolo e Arquivo, esta tem por atribuição gerenciar a entrada e saída de documentos internos e externos e preservar a memória institucional por meio de seu patrimônio documental, de forma a garantir o acesso à informação. Na unidade há sob custódia cerca de 4.000 processos. Por ora, as principais atividades e ações desenvolvidas foram: a criação da Comissão de Implementação e Acompanhamento do Código de Classificação de documentos de arquivo relativos às atividades-fim da UNILA, com o objetivo de aplicar os instrumentos arquivísticos (o plano de classificação e a tabela de temporalidade de documentos relativos às atividades meio e fim) no âmbito da universidade; a entrevista ${ }^{6}$ para a Instituição acerca das ações do arquivo; a criação da Comissão Permanente de Avaliação de Documentos (CPAD), composta por profissionais de diferentes especialidades, com a pretensão de eles contribuírem no processo de análise e

\footnotetext{
5 Informações retiradas do site da Universidade Federal da Integração Latino-Americana (UNILA). Disponível em: <https://www.unila.edu.br/assessoriaimprensa/unila-em-numeros>. Acesso em: 27 jun. 2016.

${ }^{6}$ Disponível em: <https://www.unila.edu.br/noticias/gestao-documental>.
} 
de seleção dos documentos para guarda permanente ou eliminação; e foram realizadas visitas técnicas em outras instituições, com o intuito de compartilhar ideias, conhecimentos e experiências.

Ademais, ministraram curso de Gestão de Documentos de Arquivos, visando capacitar os demais servidores da universidade quanto à importância da organização, tratamento e preservação documental. Cabe enfatizar que o curso foi requisitado pela Pró-Reitoria de Gestão de Pessoas para ser realizado, novamente, no corrente ano. Foi elaborado, também, o Manual de Procedimentos da unidade, como fonte de informação sobre as atividades desempenhadas pelo setor; produziram a minuta da Política de Gestão Documental, que está em fase de análise pela Administração, a fim de estabelecer diretrizes, orientações e normas de produção, uso, recebimento, tramitação, arquivamento e destinação dos documentos; além da elaboração de modelos e termos de documentos com o intuito de padronizar o seu formato e uso; e construíram uma página da Seção no site da universidade ${ }^{7}$, com a finalidade de divulgar e apresentar as informações da unidade ao público geral, conforme representado na Figura 1:

Figura 1 - Página da Seção de Protocolo e Arquivo no site da UNILA

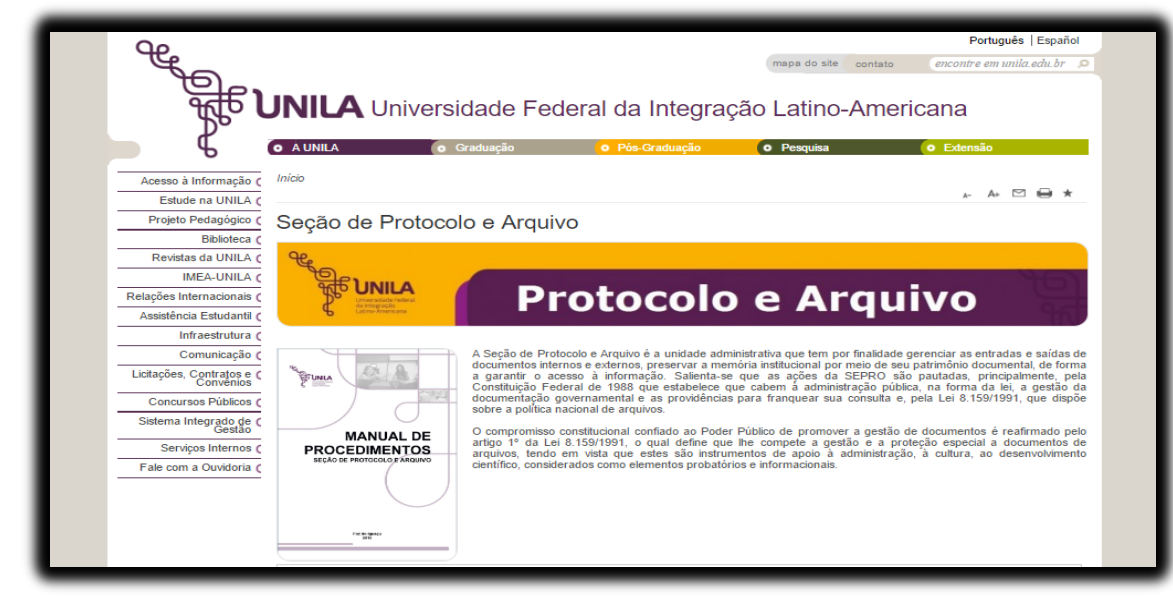

Fonte: Universidade Federal da Integração Latino-Americana

Em relação aos novos recursos tecnológicos, convém enfatizar que a

${ }^{7}$ Disponível em: <https://www.unila.edu.br/protocoloearquivo>. 
Seção é responsável pelo gerenciamento do módulo de Protocolo, do Sistema Integrado de Gestão de Patrimônio, Administração e Contratos (SIPAC), sendo assim, constantemente estão sendo aprimorados os campos do sistema, em conjunto com os analistas de Tecnologias de Informação (TI), objetivando aperfeiçoar suas funcionalidades. Além disso, estão sendo digitalizados os processos administrativos arquivados para facilitar a recuperação e o acesso das informações, e juntamente são realizadas a restauração e a higienização dos documentos e dos processos para melhorar a conservação dos registros informacionais.

Convém salientar que existe ainda uma proposta para implantar o processo eletrônico na universidade, com o propósito de reduzir os gastos públicos, economizar na produção e no acúmulo dos processos administrativos no suporte papel, tornar o andamento e a tramitação dos processos mais ágil e simplificado, diminuir o extravio de documentos, entre outros fins.

\section{CONSIDERAÇÕES FINAIS}

Acredita-se que se conseguiu e se tem conseguido conscientizar boa parte dos agentes públicos da Universidade sobre a importância da organização dos arquivos e dar visibilidade ao arquivista que lida com essa documentação, tendo em vista que o curso de Gestão de Documentos de Arquivo foi solicitado, mais uma vez, sendo que este fator demonstra o interesse dos servidores acerca da relevância do tema.

Ressalta-se, também, que o código de classificação e a tabela de temporalidade de documentos relativos às atividades-fim foram aprovados $\mathrm{e}$ disponibilizados. Recentemente, estes instrumentos foram sendo implementados e aplicados no âmbito da instituição.

Outro aspecto que foi observado é que a universidade é considerada nova ainda, pois foi criada em 2010. Contudo, nota-se que se iniciou e se desenvolveram importantes e pertinentes atividades arquivísticas por meio do apoio, comprometimento, colaboração e trabalho conjunto dos servidores envolvidos nas ações. 
Para tanto, espera-se ainda criar oportunidades de ofertas de vagas de estágios para estudantes atuarem na unidade, como também através da formação de parcerias com diferentes instituições, públicas ou privadas; além de promover novos projetos e programas relacionados aos arquivos, com a finalidade de divulgar e difundir o acervo da universidade, visando promover a participação da sociedade e atender diversos usuários com propósitos de produzir pesquisas científicas, conhecer a história da universidade, bem como garantir seus direitos de cidadania.

\section{REFERÊNCIAS}

ALBUQUERQUE, A. C. A classificação de documentos fotográficos: um estudo em arquivos, bibliotecas e museus. 2012. 287 f. Tese (Doutorado em Ciência da Informação) - Universidade Estadual Paulista Júlio de Mesquita Filho, Faculdade de Filosofia e Ciências, Marília, 2012.

ARQUIVO NACIONAL. Conselho Nacional de Arquivos. Classificação, temporalidade e destinação de documentos de arquivo relativos às atividades-meio da administração pública. Rio de Janeiro: Arquivo Nacional, 2001. $156 \mathrm{p}$.

ARQUIVO NACIONAL. Dicionário brasileiro de terminologia arquivística. Rio de Janeiro: Arquivo Nacional, 2005.

BACELLAR, C. Uso e mau uso dos arquivos. In: PINSKY, C. B. (Org.). Fontes Históricas. São Paulo: Contexto, 2005.

BERNARDES, I. P. Como avaliar documentos de arquivo. São Paulo: Arquivo do Estado, 1998.

BRASIL. Conselho Nacional de Arquivos. Resolução no 1, de 18 de outubro de 1995. Dispõe sobre a necessidade da adoção de planos e ou códigos de classificação de documentos nos arquivos correntes. Diário Oficial. Brasília, n. 204, p. 16779, 24 out. 1995, seção 1.

BRASIL. Conselho Nacional de Arquivos. Resolução n 14, de 24 de outubro de 2001. Diário Oficial. Brasília, n. 28, p. 2, 08 fev. 2002, seção 1. 
BRASIL. Lei $\mathbf{n}^{\circ}$ 12.189, de 12 de janeiro de 2010. Dispõe sobre a criação da Universidade Federal da Integração Latino-Americana (UNILA) e dá outras providências. Presidência da República. Disponível em: <http://www.planalto.gov.br/ccivil_03/_ato2007-2010/2010/lei/L12189.htm>. Acesso em: 28 jun. 2016.

BRASIL. Lei no 8.159, de 8 de janeiro de 1991. Dispõe sobre a política nacional de arquivos públicos e privados e dá outras providências. Diário Oficial. Brasília, n. 6, 1991.

BRASIL. Ministério da Educação. Portaria Arquivo Nacional no 092 de 23 de setembro de 2011. Aprova o Código de Classificação e a Tabela de Temporalidade e Destinação de Documentos de Arquivo relativos às Atividades-Fim das Instituições Federais de Ensino Superior (IFES). Diário Oficial. Brasília, n. 185, 2011.

CAMARGO, A. M. A.; BELLOTTO, H. L. Dicionário de terminologia arquivística. São Paulo: AAB-Núcleo São Paulo, 1996.

CONSELHO NACIONAL DE ARQUIVOS. Legislação Arquivística Brasileira. 2016. Disponível em:

<http://www.conarq.arquivonacional.gov.br/cgi/cgilua.exe/sys/start.htm?sid=4>. Acesso em: 27 jun. 2016.

JARDIM, J. M. O conceito e a prática de gestão de documentos. Acervo, Rio de Janeiro, v. 2, n. 2, p. 35-42, jul./dez, 1987.

LOPES, L. C. A nova arquivística na modernização administrativa. Rio de Janeiro: Papéis e Sistemas, 2000.

MORENO, N. A. Gestão documental ou gestão de documentos: trajetória histórica. In: BARTALO, L.; MORENO, N. A. (Org.). Gestão em arquivologia: abordagens múltiplas. Londrina: EDUEL, 2008. Cap. 3. p. 70-88.

OLIVEIRA, L. M. V. Política de aquisição: uma reflexão em torno das questões que orientam o processo de ampliação dos acervos institucionais. In: OLIVEIRA, L. M. V.; SILVA, M. C. S. M. (Org.). Políticas de aquisição de preservação de acervos em universidades e instituições de pesquisa. Rio de Janeiro: Museu de Astronomia e Ciências Afins, 2012. p. 117-130.

ROUSSEAU, J. Y.; COUTURE, C. Os fundamentos da disciplina arquivística. Lisboa: Dom Quixote, 1998.

SCHELLENBERG, T. R. Arquivos modernos: princípios e técnicas. Rio de Janeiro: FGV, 1974. 
SOUSA, R. T. B. Em busca de um instrumental teórico-metodológico para a construção de instrumentos de classificação de documentos de arquivo. In: BARTALO, L.; MORENO, N. A. (Org.). Gestão em Arquivologia: abordagens múltiplas. Londrina: EDUEL, 2008. Cap. 1. p. 13-52.

THOMASSEN, T. Uma primeira introdução à arquivologia. Arquivo e Administração. Rio de Janeiro, v. 5, n. 1, p. 5-16, jan./jun. 2006.

\title{
DOCUMENT MANAGEMENT OF A PUBLIC UNIVERSITY IN THE WEST OF THE STATE OF PARANÁ
}

\begin{abstract}
Introduction: This paper reports an experience of archivals activities developed in a public university in the west of Paraná. Objective: Goal was to present the main actions carried out within the institution to date. Methodology: From 2011 to the second semester committees were created, a course was teached, technical visits were carried out, a web page was created, among others actions. Results: As a result, it was noticed that the adopted practices shown to be satisfactory in regard to develop academic and administrative activities. Conclusions: It's concluded that there is interest, consideration and respect with university' servers on treatment, organization and preservation of the documental heritage of the institution.
\end{abstract}

Descriptors: Institutional archives. Document management. Documental organization.

\section{GESTIÓN DOCUMENTAL UNA UNIVERSIDAD PÚBLICA EN EL OESTE DEL ESTADO DE PARANÁ}

\begin{abstract}
RESUMEN
Introducción: En el documento se describe la experiencia de actividades de los archivos en una universidad pública en el oeste de Paraná. Objetivo: Objetivo era presentar las principales acciones llevadas a cabo dentro de la institución hasta la fecha. Metodología: Desde 2011 hasta la segunda mitad de 2016 se crearon comisiones; impartido un curso, visitas técnicas, construido una página web, entre otras acciones. Resultados: Como resultado, se observó que la práctica adoptada llegar a ser satisfactoria con respecto a la realización de actividades académicas y administrativas. Conclusiones: Se concluyó que hay interés, la consideración y el respeto de los servidores de la universidad sobre el tratamiento, organización y preservación del patrimonio documental de la institución.
\end{abstract}

Descriptores: Archivo institucional. Gestión documental. Organización de los documentos.

Recebido: 10.03. 2017

Aceito: 27.02 .2018

Inf. Inf., Londrina, v. 23, n. 2, p. $619-632$, maio/ago. 2018.

http://www.uel.br/revistas/informacao/ 